\title{
The Economic Impact of Biosimilars in Oncology and Hematology: The Case of Trastuzumab and Rituximab*
}

\author{
JACOPO GIULIANI and ANDREA BONETTI \\ Department of Oncology, Mater Salutis Hospital, Legnago, Italy
}

\begin{abstract}
Background/Aim: Biosimilar agents are biologic products that have no clinically meaningful differences in terms of quality, efficacy, safety and immunogenicity compared to an already approved reference biological product, with the potential to reduce the costs of biologics. Considering the increasing numbers of oncology biosimilars, it is important to calculate the economic impact of biosimilars in oncology and hemathology, considering trastuzumab and rituximab as examples, with their greatest budgetary impact in Oncology and Hematology Units, respectively. The present analysis was conducted to assess the pharmacological costs of trastuzumab and rituximab originator versus the corresponding approved biosimilars. Materials and Methods: Pivotal phase III randomized controlled trials (RCTS) were considered for the approved indications in neoadiuvant breast cancer $(B C)$ and in first-line treatment for advanced follicular lymphoma. Pharmacological costs necessary to get the benefit in the cancer outcomes: $i)$ time to treatment failure (TTF) and ii) pathological complete response $(p C R)$ in biosimilars and originators were calculated. The costs of drugs are at the Pharmacy of our Hospital and are expressed in euros $(€)$. Results: Our analysis evaluated 5 phase III RCTs, including 2,362 patients. The economic advantage of biosimilars versus (vs.) originator is 274 $€$ (rituximab) and from 3,283 $€$ to 6,310 $€$ (trastuzumab) per month for TTF (about $40 \%$ less than the originator). Conclusion: Combining pharmacological costs of drugs with the measure of efficacy represented by TTF and $p C R$, biosimilars of rituximab and trastuzumab are cost-effective treatments for advanced follicular lymphoma and breast cancer
\end{abstract}

Correspondence to: Jacopo Giuliani, Department of Oncology, *Presented at the 40th EORTC-PAMM Winter Meeting, February 2019, Verona, Italy.

Mater Salutis Hospital, Az. ULSS 9 Scaligera, Via Gianella 1-37045 Legnago (VR), Italy. Tel: +39 0442622364, Fax: +39 0442622469, e-mail: giuliani.jacopo@alice.it

Key Words: Trastuzumab, rituximab, biosimilars, cost of drugs.
Biosimilar agents are biological products that have been shown to be "highly similar" to an already approved reference biological product. In fact, biologics are essential to oncology care and often with high-cost components. Biosimilars have the potential to reduce the costs of biologics. According to the European Union (EU) guidelines, biosimilar therapeutics with comparable efficacy and safety profiles for the recommended indications of their respective reference originator biologics have been approved, in order to integrate biosimilars into oncology treatment paradigms and practices. In light of the relevant expenses of pharmacological interventions it should be of high importance to calculate the economic impact of biosimilars in oncology and hemathology, and considering trastuzumab and rituximab as paradigmatic examples, with their greatest impact on drug expenditure in Oncology and Hematology Units, respectively. The present analysis was conducted to assess the pharmacological costs of trastuzumab and rituximab originator versus (vs.) the corresponding approved biosimilars (1-4) and their effectiveness of the latter as treatment options.

\section{Materials and Methods}

Pivotal phase III randomized controlled trials (RCTs) were considered for the approved indications in neoadiuvant breast cancer (BC) and in first-line treatment for advanced follicular lymphoma. Each pivotal RCT of biosimilar is divided into 2 parts: i) a pharmacokinetic subset (part 1) and ii) overall response (non inferiority efficacy in the efficacy population) (part 2). We calculated the pharmacological costs necessary to get the benefit in the cancer outcomes: i) time to treatment failure (TTF) and ii) pathological complete response (pCR), between the different arms of each trial. Calculations were based on an "ideal patient" (BSA $1.8 \mathrm{~m}^{2}$; weight $70 \mathrm{Kg}$ ). The dosage of drugs was considered according to what is reported in each RCT. The costs of drugs are at the Pharmacy of our Hospital and are expressed in euros $(€)$. We assumed the following costs: rituximab originator at $248 €$ for $100 \mathrm{mg}$, rituximab biosimilar at $150 €$ for $100 \mathrm{mg}$, trastuzumab originator at $622 €$ for 150 $\mathrm{mg}$ and trastuzumab biosimilar at $370 €$ for $150 \mathrm{mg}$.

\section{Results}

We evaluated 5 phase III RCTs (1-4), including 2,362 patients $(1,088$ patients for rituximab and 1,274 patients for trastuzumab). Concerning rituximab, combining the costs of 
therapy with the measure of efficacy represented by TTF, we got the costs for obtaining the advantage for TTF for each arm of the analyzed trials. The advantage with the rituximab biosimilar (CT-P10 or GP2013) is at $274 €$ per month for TTF (about $40 \%$ less than the originator) (Table I). Similar results were obtained with trastuzumab, considering $\mathrm{pCR}$ as the reference endpoint, with $6,310 €$ and $3,283 €$ (about $40 \%$ ) less compared to the trastuzumab biosimilar versus the originator for the whole neoadiuvant treatment (Table II). This translates to an economic advantage of about $800 €$ for each cycle, and shows that results can be applied in different settings (neoadiuvant, adiuvant and metastatic) of clinical practice, based on reproducible efficacy data $(3,4)$.

\section{Discussion}

Based on the data presented here, it is easy to see that the pharmacological costs were influenced by two main factors: i) the efficacy of the therapies (strictly associated with the patients' inclusion criteria) and ii) the price of drugs used. Combining the costs of therapy with the measure of efficacy (TTF and pCR), we got the costs for obtaining the advantage in cancer outcomes. The main limitation is the cross-trial comparisons. However, to our knowledge, this is the first time a comparison of the pharmacological costs of biosimilars and the originator in oncology and hematology is linked to cancer outcomes. The pharmacological costs can also be transferred to the Italian clinical practice and, more generally, to European practice (free movement of patients and goods). The idea is to emphasize not only the cost topic, but also the method, by evaluating the combination of the pharmacological costs of drugs with the measures of efficacy (TTF, pCR).

In conclusion, through the combined analysis of the pharmacological costs of drugs and the measure of efficacy represented by TTF and pCR, biosimilars of rituximab and trastuzumab were shown to be cost-effective treatments for advanced follicular lymphoma and breast cancer. We hope for progressively more extensive use in daily clinical practice.

\section{Conflicts of Interest}

The Authors have no conflicts of interest.

\section{Authors' Contributions}

JG and $\mathrm{AB}$ contributed equally to the conception and design of the study, acquisition, analysis and interpretation of data, drafting the article and revising it critically for important intellectual content, as well as for its final approval to be published.

\section{Acknowledgements}

No funds were received to support this article.

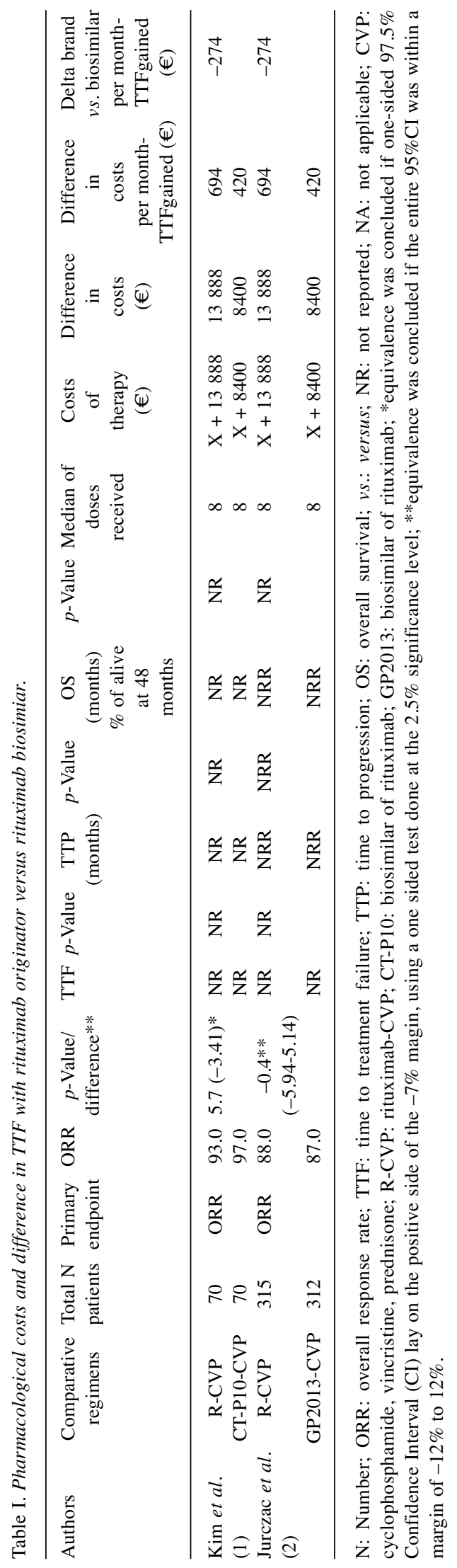


Table II. Pharmacological costs with trastuzumab originator versus trastuzumab biosimilar.

\begin{tabular}{|c|c|c|c|c|c|c|c|c|c|}
\hline Authors & $\begin{array}{l}\text { Comparative } \\
\text { regimens }\end{array}$ & $\begin{array}{l}\text { Total } \mathrm{N} \\
\text { patients }\end{array}$ & $\begin{array}{l}\text { Primary } \\
\text { endpoint }\end{array}$ & $\mathrm{pCR}$ & $\begin{array}{c}p \text {-Value/ } \\
\text { difference } \\
(90 / 95 \% \mathrm{CI})\end{array}$ & $\begin{array}{l}\text { Median of } \\
\text { doses } \\
\text { received }\end{array}$ & $\begin{array}{c}\text { Costs of } \\
\text { therapy }(€)\end{array}$ & $\begin{array}{c}\text { Difference in } \\
\text { costs }(€)\end{array}$ & $\begin{array}{c}\text { Delta brand } \\
v s . \text { biosimilar } \\
\text { for the whole } \\
\text { neoadjuvant } \\
\text { treatment }(€)\end{array}$ \\
\hline \multirow[t]{2}{*}{$\begin{array}{l}\text { Stebbing } \\
\text { et al. (3) }\end{array}$} & $\begin{array}{l}\text { Chemotherapy } \\
\text { plus trastuzumab }\end{array}$ & 278 & $\mathrm{pCR}$ & 50.4 & $\begin{array}{c}-0.04 \\
(95 \% \mathrm{CI}: 0.12-0.05)^{*}\end{array}$ & 8 & $X+15560$ & 15560 & -6310 \\
\hline & $\begin{array}{l}\text { Chemotherapy } \\
\text { plus CT-P6 }\end{array}$ & 271 & & 46.8 & & 8 & $X+9250$ & 9250 & \\
\hline \multirow[t]{2}{*}{$\begin{array}{l}\text { Von Minckwitz } \\
\text { et al. (4) }\end{array}$} & $\begin{array}{l}\text { Chemotherapy } \\
\text { plus trastuzumab }\end{array}$ & 361 & $\mathrm{pCR}$ & 41.0 & $\begin{array}{c}7.3 \% \\
(90 \% \mathrm{CI}: 1.2-13.4)^{* *} \\
1.188 \\
(90 \% \mathrm{CI}: 1.033- \\
1.366)^{* * *}\end{array}$ & 4 & $X+8093$ & 8093 & -3283 \\
\hline & $\begin{array}{c}\text { chemotherapy plus } \\
\text { ABP980 }\end{array}$ & 364 & & 48.0 & & 4 & $X+4810$ & 4810 & \\
\hline
\end{tabular}

N: Number; pCR: pathological complete response; CI: confidence interval; vs.: versus; CT-P6: biosimilar of trastuzumab; ABP980: biosimilar of trastuzumab; *for the equivalence to be accepted, $95 \% \mathrm{CI}$ for the risk ratio estimate had to fall within the margin of $0 \cdot 74-1 \cdot 35$; **risk difference (the upper bounds of the CIs exceeding the predefined equivalence margins of 13\%); ***risk ratio (RR) (the upper bounds of the CIs exceeding the predefined equivalence margins of 1.318).

\section{Informed Consent}

Not needed (no human participants were involved).

\section{References}

1. Kim WS, Buske C, Ogura M, Jurczak W, Sancho JM, Zhavrid E, Kim JS, Hernández-Rivas JÁ, Prokharau A, Vasilica M, Nagarkar R,Osmanov D, Kwak LW, Lee SJ, Lee SY, Bae YJ and Coiffier B: Efficacy, pharmacokinetics, and safety of the biosimilar CT-P10 compared with rituximab in patients with previously untreated advanced-stage follicular lymphoma: a randomised, double-blind, parallel-group, non-inferiority phase 3 trial. Lancet Haematol 4(8): 362-373, 2017. PMID: 28712940. DOI: $10.1016 / \mathrm{S} 2352-3026(17) 30120-5$

2. Jurczak W, Moreira I, Kanakasetty GB, Munhoz E, Echeveste MA, Giri P, Castro N, Pereira J, Akria L, Alexeev S, Osmanov E, Zhu P, Alexandrova S, Zubel A, Harlin O and Amersdorffer J: Rituximab biosimilar and reference rituximab in patients with previously untreated advancedfollicular lymphoma (ASSISTFL): primary results from a confirmatory phase 3, double-blind, randomised, controlled study. Lancet Haematol 4(8): 350-361, 2017. PMID: 28712941. DOI: 10.1016/S2352-3026(17)30106-0
3 Stebbing J, Baranau Y, Baryash V, Manikhas A, Moiseyenko V, Dzagnidze G, Zhavrid E, Boliukh D, Stroyakovskii D, Pikiel J, Eniu A, Komov D, Morar-Bolba G, Li RK, Rusyn A, Lee SJ, Lee SY and Esteva FJ: CT-P6 compared with reference trastuzumab for HER2-positive breast cancer: a randomised double-blind, active-controlled, phase 3 equivalence trial. Lancet Oncol 18(7): 917-928, 2017. PMID: 28592386. DOI: 10.1016/S1470-2045(17)30434-5

4 von Minckwitz G, Colleoni M, Kolberg HC, Morales S, Santi P, Tomasevic Z, Zhang N and Hanes V: Efficacy and safety of ABP 980 compared with reference trastuzumab in women with HER2-positive early breast cancer (LILAC study): a randomised, double-blind, phase 3 trial. Lancet Oncol 19(7): 987-998, 2018. PMID: 29880292. DOI: 10.1016/S14702045(18)30241-9
Received April 5, 2019

Revised May 25, 2019

Accepted May 28, 2019 